\section{Pouring Israel into a Starbucks Cup}

Cornell Hospitality Quarterly 52(2) I35-143

(C) The Author(s) 201I

Reprints and permission:

sagepub.com/journalsPermissions.nav DOI: I0.1।77/I9389655।03950I5

http://cqx.sagepub.com

\author{
By Arturs Kalnins and Laure Stroock
}

@SAGE

\begin{abstract}
An analysis of Starbucks' failed venture in Israel provides a cautionary tale of emotionally driven decisions gone wrong. For its joint venture, Starbucks worked with Delek Israel Fuel Company (DIFC), an operator of gas stations and convenience stores, among other ventures. While both firms were successful in their own spheres, their competitive advantages and corporate cultures did not mesh in attempting to operate a joint venture-particularly when business went sour. A consideration of why these two firms went forward with their venture, even though it was clear that they were not well matched, provides strong implications for managers. Three factors pushed the deal, once it began: (I) emotional commitment, (2) escalating commitment, and (3) overconfidence. First, Starbucks CEO Howard Schultz wanted his firm to open shops in Israel, but the company did not appear to conduct serious market research. Second, once it became known that Starbucks and DIFC were negotiating a deal, it became increasingly difficult for either one to back off. Third, because both firms were successful-and because Starbucks had successfully opened a chain of stores in Arab Middle Eastern nations-the two firms exhibited overconfidence and anticipated that their joint venture would necessarily be successful. The key lessons from the case are for companies to (I) choose their partners carefully, (2) be willing to exit agreements rather than to proceed with partnerships that appear problematic, and (3) avoid substituting emotion for market analysis.
\end{abstract}

\title{
Keywords
}

Starbucks; Israel; international joint ventures

Citing Starbucks' recent success stories in entering neighboring countries (Lebanon, Qatar, Saudi Arabia, Kuwait, the United Arab Emirates, and Bahrain), Peter Maslen (see Exhibit 1), president of Starbucks Coffee International, a wholly owned subsidiary of Starbucks Coffee Company, told the Israeli press in spring 2001 that he "expected Israel to be an excellent market for Starbucks, with great growth opportunities" (Berger 2001). His statement overlooked the issue that introducing Starbucks coffee in a country already accustomed to high-quality gourmet coffee and hit by a recession might prove challenging despite substantial worldwide brand recognition. Furthermore, as we discuss in this article, Starbucks chose Delek Israel Fuel Corporation (DIFC), Israel's second largest owner and operator of gasoline stations, as its partner for the venture - with unexpected results.

\section{A Lifestyle Brand}

Founded in Seattle in 1971 and named after the first mate in Herman Melville's Moby Dick, Starbucks was a small, specialty coffee roaster until 1987, when Howard Schultz acquired the company through his Il Giornale coffee bar chain. As CEO, Schultz had the vision to introduce the Italian coffee bar culture to the U.S. consumer, by characterizing
Starbucks as "the third place," a nonsmoking environment (besides home and work) where people could form a community and spend time. The Starbucks mission was "to make a difference in people's lives by leveraging the brand and the coffee experience to foster human connections." Starbucks customers came not only for coffee but also for the satisfaction of being physically inside a Starbucks coffee shop or carrying a Starbucks coffee cup around with them. This experience was promoted by the décor, the music, the predictable welcoming environment, consistent quality, quick service, and the demeanor of the "baristas." 2

\section{Business Model}

In addition to roasting and selling coffee beans, Starbucks sold fresh-brewed coffee, Italian-style espresso beverages, cold blended beverages, a variety of pastries and confections, coffee-related accessories and equipment, and a line of premium teas. Starbucks grew quickly over the years. In spring 2001, as Maslen made his prediction, Starbucks operated more than 4,300 units worldwide, serving more than 12 million customers per week in more than 20 countries (Exhibit 2). The company had generated approximately $\$ 2.2$ billion in net revenues for fiscal 2000 , of which roughly 73 percent 


\section{Exhibit 1: \\ Short Bios of Starbucks Israel Top Executives}

Giora Sarig, president of Delek Israel Fuel Corporation. Before joining Delek Israel Fuel Corporation in 2000, Sarig, 42, was general manager of the Greenberg chain of supermarkets. He had been an intricate part of Greenberg's development since its inception in 1993. Prior to joining Greenberg, he held a series of management positions with the Supersol chain.

Peter Maslen, president of Starbucks Coffee International. Prior to joining Starbucks in 1999, Maslen served as president of Tricon Global Restaurants in Europe, with responsibility for the development and growth of the Pizza Hut, Kentucky Fried Chicken and Taco Bell brands throughout Western and Central Europe and former Soviet bloc countries. He began his career in this industry with Mars Incorporated, culminating as region director, Asia, when he was recruited to PepsiCo.

was attributable to the sale of handcrafted beverages in company-operated retail outlets. ${ }^{3}$

The company's business model comprised the following three parts:

- North American retail stores, largely companyowned and -operated (every Starbucks unit was standardized, with the same coffee, interior design, and food);

- international retail stores (typically through licensing or joint venture, but also some ownership); and

- brand extension or "specialty operations" (complementary products such as the bottled coffee drink trademarked as Frappuccino and a line of premium ice creams, sold in numerous outlets).

Starbucks typically employed a "cluster" strategy by opening multiple locations within close proximity to allocate waiting lines between locations and expand its customer base. The company believed that opening multiple stores in the same area helped build the brand. Since most Starbucks stores were company-owned and not franchised, Starbucks' top management was willing to accept the sales-cannibalization risks associated with the cluster strategy. The brand spent relatively little on traditional forms of advertising. Instead, it relied on word of mouth and the ubiquity of its stores.

\section{International Expansion}

Starbucks' international expansion, which began in 1996 with its entry into Japan and Singapore, used a different pattern than in the United States. By spring 2001, the company operated 244 stores overseas and licensed another 541 (Exhibit 3). Starbucks' top management believed that the company had the potential to have at least 20,000 locations worldwide, with as many as 10,000 locations in international markets.
From a strong foothold in the United Kingdom, where it had opened more than 200 retail outlets, the company was about to enter Switzerland, its first market in continental Europe.

Although its international business model generally involved working with partners under license, Starbucks had to take an ownership stake to attract compatible partners in some countries (e.g., Japan, South Korea, and Switzerland) or even to own (or buy back) its stores (as in Singapore, Thailand, and Australia). In most countries, Starbucks chose partners with an expertise similar to its own. In Hong Kong, for instance, Starbucks had a licensing agreement with Maxim's Catering Ltd., a local retailer operating premium bakeries. In Japan, Starbucks formed a 50-50 joint venture with Sazaby Inc., a Japanese retailer and restaurateur.

Starbucks' aggressive international expansion typically met little resistance. Only a few countries had proved challenging. In China, for example, major disagreements with a partner, a Chinese private equity firm, had forced Starbucks to buy out its partner's share to gain operating control. "They were focused on fast returns and exit strategies; we had longterm objectives in China," commented an international retail financial analyst at Starbucks. ${ }^{4}$

\section{Starbucks in the Middle East}

In 1998, M.H. Alshaya Co., a Kuwaiti retailer specializing in international franchise retailing in the Middle East, approached Starbucks to buy local franchising rights, but at that time, Starbucks was not interested in offering international franchises in the region. Alshaya was a family-owned business active in real estate development, hotel management, warehousing, car dealerships, food service, and retail operations. In 2000, Alshaya had 190 stores and 23 brands in its franchise management business (Youssef 2000). Alshaya was able to partner with Seattle Coffee (at the time, a rival of Starbucks), and opened the first Seattle Coffee store in Kuwait in mid-1998. When Starbucks purchased Seattle Coffee six months later, Starbucks offered Alshaya the rights to become its franchisee in the Middle East.

After evaluating Alshaya's regional operations and various markets in the region, a team of Starbucks executives decided on several locations and on the size of the stores to be opened. Alshaya and Starbucks signed a ten-year multijurisdictional licensing agreement giving Alshaya rights to open Starbucks stores in Saudi Arabia, Kuwait, Oman, Bahrain, United Arab Emirates, Qatar, and Lebanon. The partnership was a good match, and by 2001, Alshaya managed more than 30 Starbucks stores in the region. "In the Middle East, Starbucks has proven to be a hit with the local customers," said CEO Mohammed Alshaya. "Starbucks business has performed exceptionally well and the concept has been positively received throughout our markets" (Business Editors 2003). Howard Behar, Starbucks International general manager from 1995 through 


\section{Exhibit 2:}

Starbucks Locations and Number of Stores (as of May 200I)

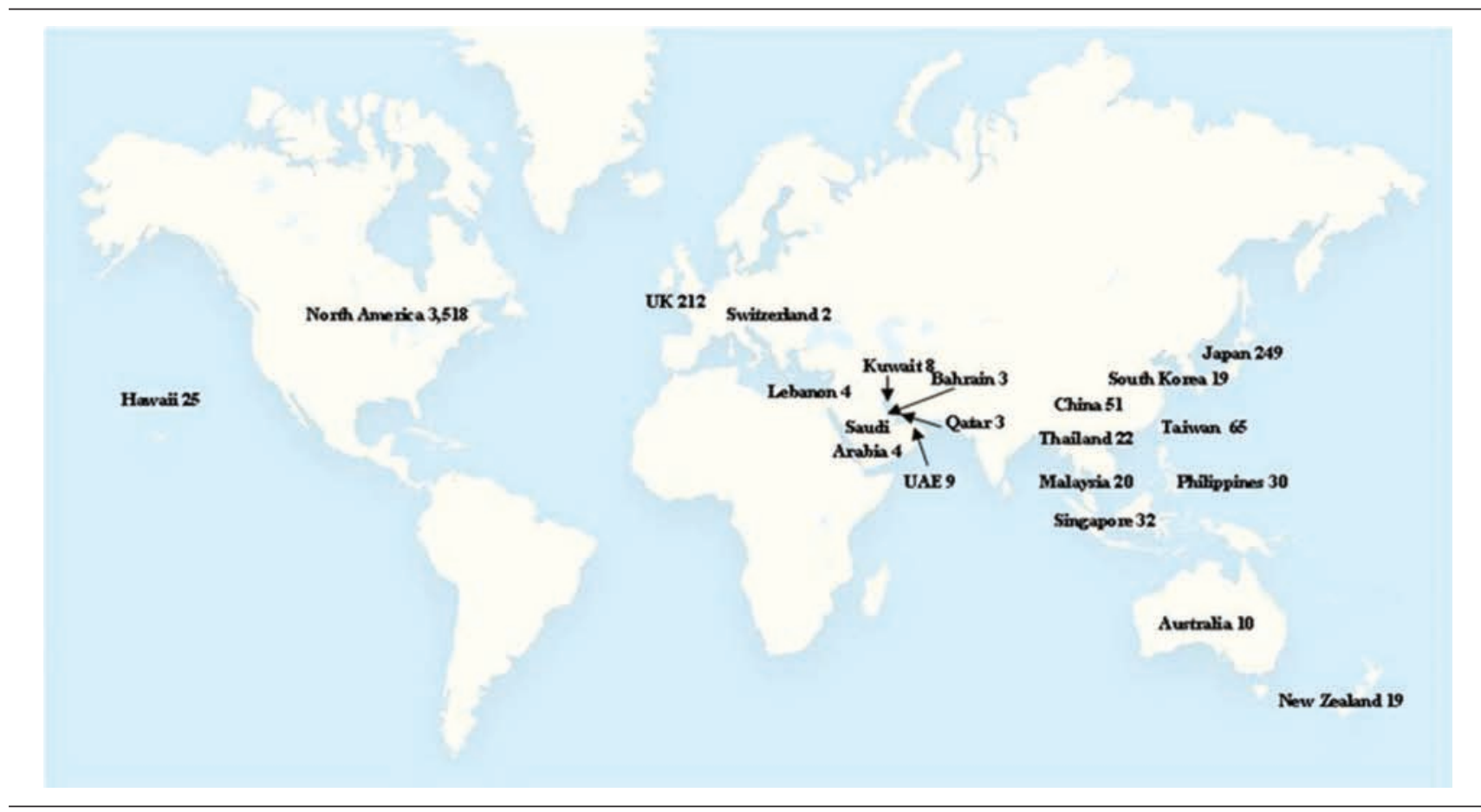

Source: Company reports.

\section{Exhibit 3:}

Starbucks Store Opening Data (Starbucks Units)

\begin{tabular}{|c|c|c|c|c|}
\hline Stores Open at Year-End & I998A & I999A & $2000 A$ & $200 I E$ \\
\hline \multicolumn{5}{|l|}{ North America } \\
\hline $\begin{array}{l}\text { Company-operated } \\
\text { stores }\end{array}$ & 1,622 & 2,038 & 2,446 & 2,946 \\
\hline Licensed stores & 133 & 179 & 530 & 930 \\
\hline \multicolumn{5}{|l|}{ International } \\
\hline $\begin{array}{l}\text { Company-operated } \\
\text { stores }\end{array}$ & 66 & 97 & 173 & 273 \\
\hline Licensed stores & 65 & 184 & 352 & 552 \\
\hline Total stores & 1,886 & 2,498 & 3,501 & 4,701 \\
\hline
\end{tabular}

Source: Company reports.

1999, commented that "Starbucks is proud to have found a great partner who not only has expertise in the region's marketplace, but shares our business principles and people values" (Business Editors 1999).

\section{Entering Israel}

During a trip to Israel in 1998, Howard Schultz observed what he considered to be a market opportunity. While dining at the King David Hotel, a Jerusalem landmark and Israel's most famous and luxurious hotel, Schultz declared that (although he enjoyed his trip) "the coffee was not so good" (Klein 1998). He announced that by 2000, Starbucks would set up ten stores in Israel, as it spread throughout Europe and Asia. "People will taste the difference in Starbucks' coffee," he argued.

In general, Schultz was very excited about his visit. "I am blown away. I had a sensory overload," he said at the time. "I don't think I'll ever be the same after this" (Klein 1998).

\section{The Musical Chairs of Possible Partners}

After Schultz's visit, Behar visited Israel several times, seeking a partner who was a good match. "We have not yet found the 'match' we're looking for, the partner who is right for us," said Behar in an April 2000 interview. "All the concerns with whom we met are excellent, but it doesn't mean they want us, and they also have their businesses to manage" (Kotan 2000).

What in fact was the "match" that Starbucks was looking for? Behar explained,

The most important element is shared values. I'm not referring to shared culture, but shared values. Firstly, the attitude towards employees. At Starbucks, employees come first, because if you look after employees, they'll 
look after customers. Secondly, product quality; thirdly, customer service; fourthly, don't be greedy-you have to give love before you receive it. Beyond that, you need real estate experience and knowhow and you need people within the organization itself to take it upon themselves. The final and least important thing is capital. (Kotan 2000)

Five months later, the Israeli press reported that a deal had been reached with DIFC and with Yair Hasson, previously a principal with U.S.-based Food Courts, Inc., and then the part-owner of the Israeli Burger King franchise. DIFC and Hasson would each own 40 percent of the venture, while Starbucks would hold the remaining 20 percent (Globes 2000). First, DIFC appeared to be out, apparently frustrated by Starbucks' lack of support for plans to incorporate Starbucks units into its gasoline stations. Then Hasson was out and DIFC was back in. Hasson was known for his food-service experience, his entrepreneurial spirit, and his ability to respond quickly to market changes. The initial group of management trainees sent from Israel to Starbucks' extensive training program at its Seattle headquarters had been enthusiastic about Hasson's leadership and expressed disappointment about his resignation (Sharon-Rivlin 2002b).

After the maneuvering, Starbucks signed an agreement with DIFC, which would hold 80.5 percent of the joint venture, named the Shalom Coffee Co., while Starbucks Coffee International would hold the remaining 19.5 percent. Starbucks would have the option to increase its share to 50 percent at a later date. Under the partnership terms, DIFC would pay Starbucks $\$ 250,000$ for the franchise rights, plus 6 percent of turnover (Sharon-Rivlin 2002a). DIFC agreed that it would not place Starbucks shops in its gasoline stations until the brand was firmly established in Israel.

\section{Delek Israel Fuel Corporation (DIFC)}

With 227 Delek stations (24 percent of the market), DIFC was the second largest distributor of fuel in Israel. Appropriately, "Delek" is the Hebrew word for gasoline. DIFC was involved in four activities (Exhibit 4): (1) operating or leasing the 227 gas stations; (2) the operation of more than 40 onsite twenty-four-hour, seven-days-a-week convenience stores; (3) marketing and distribution of fuel and oil products to gas stations; and (4) direct distribution of fuel (e.g., to government offices) (Harverd and Raven 2007). In conjunction with the C-stores, DIFC operated its own chain of Menta fast-food restaurants. It also had just acquired Mepco Express, which had 234 filling stations and convenience stores, mostly in Virginia and Tennessee, for \$234 million ("Delek Completes Acquisition" 2001).

DIFC's investment in Mepco and in Starbucks was part of the new entrepreneurial strategy of the Delek Group, which had just been reorganized after a hostile takeover in 1998
(Haoun 1998). To encourage its subsidiary companies to invest in new opportunities, Delek granted subsidiary management stakes in their companies and provided them with the necessary capital to expand their business (Harverd and Raven 2007). Some new ventures, including Shalom Coffee, appeared to be quite unrelated to the DIFC core businesses. As Giora Sarig, DIFC's president, joked to the press, "the only connection between gas stations and Starbucks is that we both sell black liquid" ("How Do You Say 'Frappuccino' in Hebrew?" 2001).

\section{Starbucks' Strategy in Israel}

After a failed bid to acquire Arcaffe, Israel's top coffee shop chain, the company reverted to the original plan: to launch ten shops in its first year and reach eighty stores within four years. This would make Starbucks the largest coffee shop chain in Israel, for a total investment of \$20 million. Because of security concerns, Starbucks focused first on the Tel Aviv area rather than Jerusalem. The first shop was to open in September in Tel Aviv's Kikar Rabin. The second store would open four days later on Sderot Rothschild, a popular Tel Aviv boulevard.

As usual, Starbucks would mostly rely on its brand name and word of mouth to attract customers. Starbucks also counted on the Israeli adulation for American brands. Sarig explained, "We are bringing the romance of coffee to Israel and we'll educate the Israeli public in coffee drinking" (Kaye and Bloomberg 2001).

The business plan called for three kinds of stores: (1) the "flagship store," a purpose-designed cafe; (2) "inline stores," mini-cafes designed for malls and other public institutions like hospitals; and (3) "kiosks" for quick coffee pickup and for takeaway. As agreed, there would be no initial connection between Starbucks stores and Delek gas stations or convenience stores. Starbucks' coffee pricing would be positioned at the high end of the market. In addition, the company briefly negotiated with supermarket chains Super-Sol and Blue Square Israel to open Starbucks kiosks within the supermarkets. Similar plans for rail terminals were discussed with Israel Railways (Blackburn 2002).

\section{The Israeli Coffee Shop Market and Culture}

According to industry estimates, the average Israeli drank 110 liters of coffee per year, nearly twice as much as the average American (60 liters/year), and even ahead of the average European (90 liters/year) (Salomon n.d.). Moreover, Israeli coffee culture was well developed, although the taste for high-quality coffee was a recent phenomenon dating from the early 1990s. Before that, the Israelis consumed "café botz" ("mud coffee," or Turkish coffee), poor-tasting coffee powder, or Nescafé. Lacking any native Jewish coffee tradition, 


\section{Exhibit 4:}

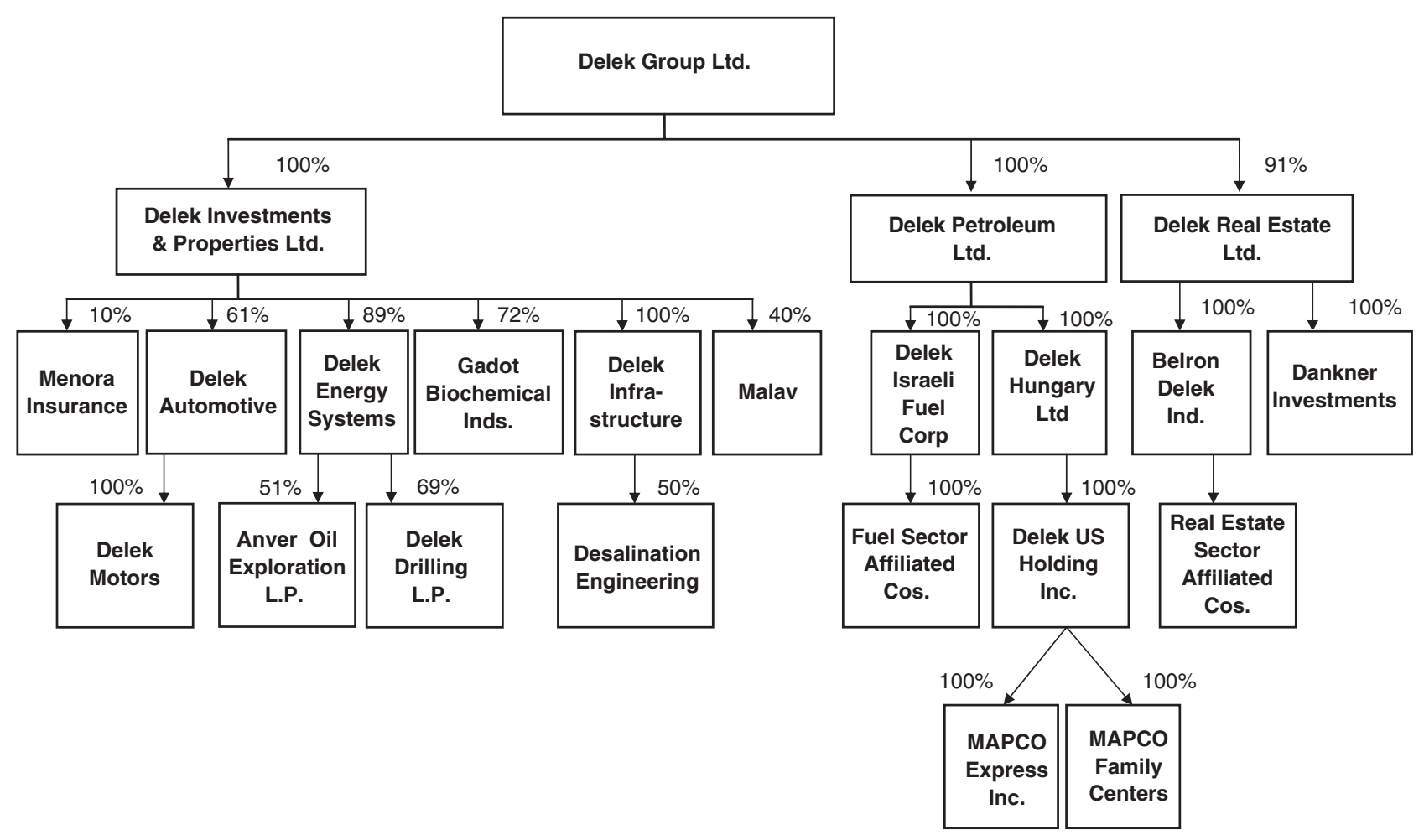

Source: Company Report (2004).

Israelis had adopted espresso as their standard. Illy, Lavazza, and Segafredo were household words in Israel, and the preparation of espresso was accepted as a form of art. It was estimated that that some five hundred coffee bars had opened up in Israel between 1995 and 1998, or approximately one for every twelve thousand residents (Klein 1998).

Cafés had always been an integral part of Israeli urban culture, particularly in Tel Aviv and Jerusalem. For both Arab and Jewish populations, cafés offered a culturally neutral space, and most coffee houses also offered a menu of alcoholic drinks, often including combinations of coffee shots and spirits or liqueurs. Like their counterparts in Europe, most Israeli cafés, even the humblest, offered food and table service. The concept of self-service and takeout coffee was unusual when it was introduced by Arcaffe cafés.

\section{Competition}

In the urban areas, Starbucks faced competition from established Israeli coffee chains, such as Arcaffe, Aroma, and Ilan's, and from independent coffee shops. Despite the recession and terror attacks, the Israeli coffee chains continued to grow. Aroma had eight cafés, with another three scheduled to open in summer 2001. Arcaffe had ten shops and planned on opening four more in 2002 (Blackburn 2002). "We are good in a recession because we are affordable. People can afford to splash out on a good coffee and a croissant," explained Arcaffe's CEO. "We are a substitute for going out, when things get rough it's a good alternative," added Arcaffe's founder (Blackburn 2002). In 1995, Arcaffe had successfully introduced in Israel the concept of "fast gourmet with ambience." Each Arcaffe offered the same menu and a similar same look and feel, but the décor - designed by an Italian company-was always different for each café.

The local competition was not overly concerned about the entrance of Starbucks, and at least one critic openly derided the company. Announcing the arrival of Starbucks, an Israeli food critic Esther Salomon predicted that Starbucks' bitter coffee would find no place with the discerning Israeli palate. Describing Starbucks coffee as "simply mediocre," Salomon (n.d.) wrote that it was "one step up the evolution chain from floor washing water." 


\section{Two Years of Troubles}

From the start, Starbucks sales were poor and its shops empty. The joint venture sustained a heavy operating loss amounting to $\$ 6$ million from 2001 to 2003 . In July 2002, the Delek Group fired Shalom Coffee's entire management team. ${ }^{5}$ One outcome of the firings was panic spreading from the executive level to middle management, severely affecting motivation (Sharon-Rivlin 2002b). One year into the deal, in July 2002, DIFC's attempt to sell its stake in the joint venture failed.

By 2003, only six shops were opened (rather than the planned eighty): three in Tel Aviv, and one each in Herzliya, Kfar Saba, and Ra'anana. In contrast to Starbucks' "cluster" strategy in the United States, the physical distance between the Starbucks Israel branches was so great that they failed to generate a critical mass (Sharon-Rivlin 2002b).

Finally, in April 2003, DIFC tried to get Starbucks to increase its stake in Shalom Coffee to 50 percent. When Starbucks refused, the joint venture was dissolved and the six stores were closed. Although Starbucks attempted to put a positive spin on these events, the official reasons given"market challenges: economy and Middle East turmoil"—_did not appear credible given the contemporaneous success of the local Israeli coffee shop chains.

Starbucks CEO Schultz made it known in 2005 that he wished the company could try again in Israel, a reentry that would likely be even more difficult in 2005 than the 2002 attempt, especially since the major local coffee shop chains were all expanding rapidly in 2005 (Sharon-Rivlin 2005).

\section{Analysis: Why Starbucks Failed in Israel}

Starbucks' failure in Israel stems almost entirely from its choice of an inappropriate partner. On the surface, that appears to be all the explanation that is needed, but it is essential to examine the underlying issues. The particular advantages of a firm such as DIFC likely led to decisions and actions that may have appeared logical from DIFC's point of view, but that ultimately precipitated the Starbucks failure. We will discuss these in detail below, but first let us consider why Starbucks chose a partner that even cursory inspection would indicate was incompatible. We see three concepts from management theory that address this question: (1) emotional commitment, (2) escalating commitment, and (3) overconfidence. As we explain, our consideration of these factors leads to an ironic but valuable conclusion: to wit, a company's strong desire to be present in a country, together with the company's successes in the past in similar countries, may actually combine to increase the likelihood of failure.

\section{An Unbridgeable Gulf}

The competitive and cultural gulf between the two companies cannot be exaggerated. DIFC was in the business of selling a product that consumers find difficult to differentiate by brand - essentially a commodity. While most companies attempt to differentiate their goods, this is nearly impossible for commodities. Instead, commodity-driven firms must focus on efficiency, as Michael Porter (1980) explains:

In some industries, there are no opportunities for focus or differentiation - it is solely a cost game - and this is true in a number of bulk commodities.

We do not have enough information to do a full analysis of DIFC's advantages at the retail and service level, but we believe that one of its competitive advantages involves efficiency in distribution. ${ }^{6}$ In contrast, Starbucks' entire focus is to gain competitive advantage by differentiating the product in the eyes of consumers. Such an advantage relies less on its coffee than on capabilities needed to create the "third place," such as human resources (recruiting and training the appropriate people) and interior design. Judging by DIFC's portfolio of business ventures shown in Exhibit 4, it is unlikely that they have capabilities in these areas.

As a consequence, the Shalom Coffee venture's strategy was not clearly focused on either efficiency or on differentiation, and it is extremely difficult to base competitive advantage on both strategies. Michael Porter (1980) compellingly argues that such firms will often remain "stuck in the middle" without decisive advantages in either area. We see Shalom Coffee as stuck in the middle.

DIFC's termination of top executives, together with onethird of its workforce, highlights the incompatibility of the DIFC and Starbucks corporate cultures. True to its roots, DIFC was focused on increasing efficiency. This action ran entirely contrary to the Starbucks culture, which is focused on developing and supporting its employees. Thus, DIFC fired Starbucks' employees when performance was beneath expectations, that move was opposed by Starbucks' corporate office, and the result of this turmoil was panic within the organization. Furthermore, DIFC's desire to open Starbucks' outlets in its gas stations, and later in supermarkets, suggests again that the mentality of a nondifferentiable product retailer has spilled over and dominates the venture.

\section{Let's Call the Whole Thing Off}

With the benefit of hindsight, it is clear that this joint venture should not have been consummated, but the two companies were determined to go forward. The case presents suggestive evidence of why this occurred, based on three concepts found within management theory: (1) the role of an emotional 
commitment to a market, (2) an escalation of commitment, and (3) overconfidence that results from past successes.

\section{Emotional Commitment and Escalation}

In a landmark 1966 book, The Foreign Investment Decision Process, Yair Aharoni studies the sizable but risky business investments in Israel made by the American Jewish community. One of Aharoni's main findings was that the investment process of the Jewish Diaspora was significantly influenced by strong psychological and emotional ties to Israel. Howard Schultz's many favorable comments after his Israel trip are an example. Aharoni's book is also known for articulating a form of what later became known as the "escalation of commitment": during the exploratory and negotiation phases of the investment decision process, the potential foreign investor (in this case, Starbucks) develops commitments and spends resources to obtain information, and thus becomes committed to proceeding with the venture, even if subsequent information suggests caution. The emotional and psychological ties represent one aspect of such commitment, along with the reputational implications of press announcements and contractual implications stemming from agreements with partners. ${ }^{7}$

Starbucks appears to have fallen into this commitment trap. The three-way partnership with Yair Hasson and DIFC probably would have been a far more palatable proposition than the subsequent partnership with DIFC alone. Yet after Hasson's departure, Starbucks apparently felt too committed to withdraw from the deal, or maybe (over) confident enough to continue with a very different venture: a partnership with a company with no food-service experience, an emphasis on efficiency, and an incompatible attitude towards expansion and employees.

\section{Overconfidence}

Complementing the emotional commitment to Israel, Starbucks' high level of confidence likely caused them to proceed with their partnership with DIFC even after Hasson left. The confidence appears to have increased as a result of the successful joint venture with Alshaya throughout the Arab Middle East and, more generally, with their international successes. A type of systematic overconfidence known as biased self-attribution has been consistently documented in the social science literature. ${ }^{8}$ Biased self-attribution is the tendency to attribute past successes to ability and past failures to chance. The adage "Success has many fathers, while failure is an orphan" is an illustration of biased self-attribution. This bias results in an overvaluation of the accuracy of one's judgment, a finding that helped Daniel Kahneman win a Nobel Prize (see Kahneman and Tversky 1982). Starbucks is not alone in this situation, and the joint venture fits a pattern.
Because overconfidence leads to worse judgments, companies will experience greater levels of failure, as found by Kalnins (2005) in a study of 142 U.S. food-service concepts. That study found that companies that announced the most ambitious plans when entering a foreign market, such as building one hundred shops or being the biggest in a country, were the most likely to fail.

Even granting that every entrepreneur needs a healthy dose of confidence, we see several explicit examples of overconfident behavior in the case, beginning with ambitious announcement of plans for eighty or one hundred Starbucks stores, along with plans to be the largest coffee shop chain in Israel. Beyond that, Howard Schultz's public comment about the poor coffee at the King David Hotel also suggests an attitude of overconfidence. While Schultz's assessment of the King David's coffee may well be accurate, the idea that this insight was sufficient to consider an Israeli venture is naive at best. Surely Schultz is aware that a sample size of one hotel does not constitute a competitive analysis. More perplexing was another comment that he made, to the effect that Starbucks had a decisive advantage because it has twenty varieties of coffee, whereas most Israeli operations have but one. He should have been more concerned about the quality of the coffee, relative to that of the competition, and about its compatibility with local tastes.

Starbucks' many successful international ventures, and particularly the successful Middle East joint venture with Alshaya, leads to a conclusion of self-attribution. The apparent lack of due diligence in analyzing the Israeli market stands in stark contrast to the extensive preparations that Starbucks conducted before initiating the venture with Alshaya, including the dedicated Starbucks team that participated in the location choices. Far from being similar to the Alshaya countries previously entered, Israel appears to have had a much more developed coffee culture (see O'Grady and Lane 1996). In addition, note Alshaya's extensive experience dealing with international franchisors, something that DIFC had little experience with.

Successful on his own turf, DIFC president Sarig shows an equal level of overconfidence. First, his statement, "We are bringing the romance of coffee to Israel and we'll educate the Israeli public in coffee drinking," is particularly troubling, given that he himself was involved in a failed effort to buy Arcaffe. Did he really believe that Israelis needed education about coffee drinking? If that statement did not have Starbucks reconsidering this joint venture, perhaps they should have done so when Sarig joked that DIFC and Starbucks both sold "black liquid." This statement makes it clear that DIFC appeared to be untroubled by their lack of experience of products differentiated by service quality.

To summarize, a combination of an emotional connection and overconfidence led Starbucks to persist in negotiations to enter a market it may well have otherwise left alone. Once 
Starbucks had negotiated long enough, it is likely that commitments to the partners had escalated to the point that Starbucks did not feel it could leave the venture, even with a suboptimal final partner. The differences between partners then led to several major operating decisions that were inconsistent with Starbucks' traditions and common practice. This analysis leads to several important implications for managers considering foreign ventures.

\section{Implications for Managers: A Joint-Venture Checklist}

- Perform an analysis of a partner's competitive advantages. Are they capable of supporting your company's product or service? Ask whether you would be happy to work with this partner in your home country. If the answer is not at least a qualified "yes," be cautious about proceeding.

- When a partnership changes its structure, in this case due to the exit of a partner, the venture must be considered to be entirely new. All assumptions need to be revisited, including market penetration, sales forecasts, and staffing.

- When negotiating with multiple partners, ensure that all agreements are contingent on all partners remaining in place. This way, a firm can exit from an agreement that no longer includes a key partner.

- Ask if any common practices of your firm, such as policies for expansion, are being contradicted in a particular venture. If so, why? Sometimes deviation from typical practices and even basic principles may well be appropriate given the idiosyncrasies of many foreign markets. However, if no clear rationale emerges for the deviation, reconsider. "That is how the partner wants to do it" is not sufficient for an answer.

- Explicitly recognize when an emotional component exists in the desire to enter a particular market. Ask whether the country would be under consideration at all without the emotional component. Additionally, is the company willing to operate at a loss to maintain a presence in the country? If so, ask whether the partner feels the same way. If a partner only has pecuniary motives, as most businesses do, it may be impossible to maintain a relationship. Solo entry might be required.

- Even the most successful companies in the world fail in specific endeavors. Therefore, when planning a venture, conduct a thought exercise where previous success is removed from the equation. What actions would be undertaken before the commencement of the venture if the company were an unknown commodity with little previous success or experience? Consider taking some of these actions even if the company is very much a known commodity with many previous successes.

- Even well-known brands still must prove themselves in every new market. Loyalty to locally successful companies is often far stronger than is curiosity about a well-known but locally untested international brand name.

\section{Declaration of Conflicting Interests}

The author(s) declared no conflicts of interest with respect to the authorship and/or publication of this article.

\section{Funding}

The author(s) received no financial support for the research and/or authorship of this article.

\section{Notes}

1. Starbucks' website, accessed April 10, 2008.

2. Starbucks' baristas received training in customer service and basic retail skills, as well as "Coffee Knowledge" and "Brewing the Perfect Cup" classes. They were taught to anticipate the customer's needs and to make eye contact while carefully explaining the various flavors and blends.

3. Starbucks' 2000 Annual Report.

4. Based on a 2007 interview in the author's strategic management class.

5. Starbucks at first attempted to retain CEO Micki Kenan as its own rep in Israel (Sharon-Rivlin 2002a).

6. See, e.g., Bradley, Ghemawat, and Foley (1994). I note, however, that Delek may not necessarily have advantages in distribution or retail operations at all. It is not clear that forward integration in these areas add value to an oil refining company. Consider for example the recent decision by Exxon-Mobil and other major refiners to leave the retail business, specifically because they feel they lacked advantages in that area.

7. The seminal work (fifteen years after Aharoni) that articulates the general phenomenon is Staw (1981).

8. For a managerial application, please see Wagner and Gooding (1997).

\section{References}

Aharoni, Y. 1966. The foreign investment decision process. Boston, MA: Harvard Business School Press.

Berger, Sharon. 2001. Starbucks to open here later this year. Jerusalem Post, April 22.

Blackburn, Nicky. 2002. For the love of a good cup of coffee. Jerusalem Post, July 25.

Bradley, Stephen, Pankaj Ghemawat, and Sharon Foley. 1994. Wal-mart Stores, Inc. Harvard Business School Case 9-794-024, Boston, MA. 
Business Editors. 1999. Starbucks coffee company opens first store in Kuwait; expansion into the GCC countries to follow. Business Wire (New York), February 9.

Business Editors. 2003. Starbucks steaming toward long-term profitability and growth internationally. Business Wire (New York), June 20.

Delek completes acquisition of Mepco Express filling stations. 2001. Alexander's Gas and Oil Connections Company News, February 7.

Globes. 2000. International coffee shop chain Starbucks to operate in Israel with Yair Hasson, Delek. September 29.

Haoun, David. 1998. Delek to fire third of workforce on becoming private co; will then make huge issue in US. Israel's Business Arena, October 26.

Harverd, Dan, and Jonathan Raven. 2007. Delek Group. Deutsche Bank Analyst Report, June 19.

How do you say "frappuccino" in Hebrew? 2001. Israel Faxx, July 31. IsraelNationalNews.com.

Kahneman, Daniel, and Amos Tversky. 1982. On the psychology of prediction. In Judgement under uncertainty, ed. Daniel Kahneman, Paul Slovic, and Amos Tversky. Cambridge, UK: Cambridge University Press.

Kalnins, Arturs. 2005. Biting off more than they can chew: Unfulfilled development commitments in international master franchising ventures. Cornell Center for Hospitality Research Report 5 (12).

Kaye, Helen, and Bloomberg. 2001. Starbucks: Israel's not too hot for us. Jerusalem Post, July 26.

Klein, Amy. 1998. The world in a coffee cup. Jerusalem Post, October 9.
Kotan, Osnat. 2000. Eventually we'll get to Israel, but won't take over the market. Globes, April 27.

O'Grady, Shawna, and Henry W. Lane. 1996. The psychic distance paradox. Journal of International Business Studies 27 (2): 309-33.

Porter, Michael E. 1980. Competitive strategy. New York, NY: Free Press.

Salomon, Esther. n.d. Move over Starbucks: Israel's upside down. Coffee Saga. http://www.zeek.net/604coffee/index.php?page=2 .

Sharon-Rivlin, Vered. 2002a. Delek pressing Starbucks to buy its Starbucks Israel stake. Israel Business Arena, July 10.

Sharon-Rivlin, Vered. 2002b. Make mine Turkish: Ten reasons why Starbucks isn't making inroads in Israel. Globes, August 5.

Sharon-Rivlin, Vered. 2005. Starbucks mulls buying Israeli cafe chain: Starbucks' Howard Schultz feels hurt that Israel is the only market he ever had to abandon. Globes, April 3.

Staw, B. M. 1981. The escalation of commitment to a course of action. Academy of Management Review 6 (4): 577-87.

Wagner, J. A., and R. Z. Gooding. 1997. Equivocal information and attribution: An investigation of patterns of managerial sensemaking. Strategic Management Journal 18 (4): 275-86.

Youssef, Susan. 2000. Wake up and smell the market-US franchise Starbucks was gained - only after rival group was bought out. Lebanon Opportunities (Beirut), May 1.

\section{Bios}

Arturs Kalnins, Ph.D., is an associate professor at the Cornell University School of Hotel Administration (Atk23@cornell.edu), where Laure Stroock is a research associate (Lm276@cornell.edu). 